\title{
THE RELATIONSHIP IN MAN OF CEREBRAL ACTIVITY TO BLOOD FLOW AND TO BLOOD CONSTITUENTS
}

\author{
BY
}

\author{
W. G. LENNOX, F. A. GIBBS, AND E. L. GIBBS
}

From the Department of Neurology, Harvard Medical School, Boston, Mass., U.S.A., and the Neurological Unit, Boston City Hospital

(RECEIVED 27TH APRIL, 1938)

This title limits us to a discussion of the human subject. In addition we shall not deal with pathological states of either the brain or the cerebral blood vessels, nor shall we stop to point out how little is known about the subject of vascular morphology in relation to intelligence. As a preliminary to our paper we wish to clarify a prevailing confusion of thought regarding the relative importance of the central nervous and the cardiovascular systems. Too many look on the brain as entirely at the mercy of the circulation and helpless in the face of failing blood-borne supplits. The relationship between brain and blood is reciprocal, but emphatically is one in which the brain is master ; the circulation is servant.

We shall briefly summarize certain findings which bear on the title of this paper.

\section{Cerebral Activity and Total Blood Flow}

If this subject were being presented in the last century, physiologists and clinicians alike would have stressed the importance of circulation. Our medical ancestors had the belief that humours were important determinants of behaviour, and our immediate predecessors interpreted many nervous and mental states in terms of cerebral blood flow. Plethora and cerebral congestion was the cause of multiple symptoms calling for blood-letting. On the other hand, cerebral anæmia was believed to cause phenomena ranging from sleep to fits. It is now realized that changes in the normal activity of the brain, even to the point of abnormality, ordinarily are the cause and not the result of a concomitant alteration in cerebral blood flow.

Activity of muscle is accompanied or followed by the opening up of the capillary bed in the muscle. Similarly, it might be expected that increased mental activity is accompanied by an increased cerebral flow. In this important 
field, observations are all too scanty. While subjects were do ing sums in mental arithmetic, Lennox and Leonhardt (1931a) measured the oxygen content of blood leaving the brain by the way of the internal jugular vein, and Carmichael, Williams, and Doupe (1937) recorded the alterations in cerebral pressure by means of a needle in the cistern. Both of these methods, though open to objections, pointed to an increase of blood flow during mental work, the result probably of an increase of systemic blood pressure. As for localized changes, Fulton (1928) noted an increase in the bruit when a patient with an arterio-venous aneurysm of the occipital lobe read in a dim light. In all cases, however, these circulatory increases are the result of cerebral activity, and not the cause. Such changes in total flow as occur are less than those which are constantly occurring fortuitously, and they are probably not significant. Also, if blood pressure and flow are artificially but only moderately decreased, mental performance is not affected. Finally, drugs which greatly alter central nervous system activity, notably the sedative, do not, according to the flow recorder experiments of Lennox et al. (1935b) and of Gibbs et al. (1935a), significantly alter cerebral blood flow unless there is coincident change in systemic blood pressure.

Particularly interesting are those manifestations which occur intermittently and, usually, involuntarily. Are they the result of a sudden decrease in cerebral flow? In observations by means of a thermo-electric flow recorder inserted in the internal jugular vein it was found that no alteration in flow took place with the onset of natural sleep or with attacks of narcolepsy (Gibbs et al., $1935 b$ ), or with seizures either of the petit mal or the grand mal type (Gibbs et al., 1934). In the case of grand mal, blood flow was greatly increased during the seizure, due to the increase in blood pressure and the accumulation of carbon dioxide in the blood. Also, the oxygen content of the blood leaving the brain was not sufficiently low to be directly responsible for the symptoms (Lennox et al., 1936a). These observations deal with alterations in the total blood flow of the brain. There may be spasm of vessels in localized regions which would not affect the total flow, but would be of clinical significance. As regards epilepsy, there is weighty evidence against this hypothesis of localized vascular spasm.

\section{Effect of Temporary or Functional Alterations of Flow}

In this and the succeeding section we shall deal with evidences of two kinds pertaining to cerebral activity : first, consciousness, and second, the electrical activity of the cortex.

More attention is commonly paid to a decrease than to an increase of blood flow in the head. Consideration of the subject is complicated because the symptoms are different in acute and in chronic anæmia. Apparently in states of blood deficiencies which are gradual in onset, the body or the brain (or both) make adjustments which, in spite of the handicap, permit brain function to continue. The mechanism of the adaptation is a subject which requires future study. Defective circulation to the brain with resultant decrease in cerebral 
activity can be brought about either by decreasing the arterial pressure or by increasing the venous pressure. We shall first discuss observations in which blood pressure was drastically reduced.

In the upright position, the cerebral circulation is maintained only by active neuro-vascular adjustments which are easily deranged. We have recorded both blood pressure and cerebral (internal jugular) blood flow in patients with orthostatic hypotension (natural or induced) and with irritable carotid sinus reflex. In these patients, unconsciousness was preceded by great fluctuations in cerebral blood flow and blood pressure, and was accompanied by a plummetlike drop in both (Lennox, et al., 1935a).

Of particular interest are observations of the cortical electrical activity of subjects when the cerebral blood flow is acutely reduced. We have recently

CHANGES IN THE ELECTRO-ENCEPHALOGRAM WITH SYNCOPE FROM CRITICAL FALL IN BLOOD PRESSURE (CAROTID SINUS REFLEX)

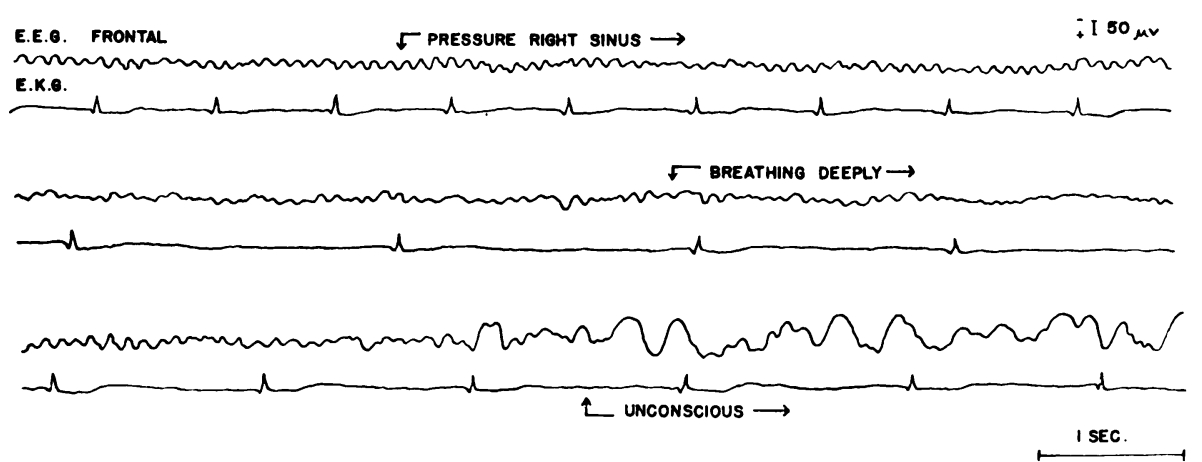

Fig. 1.-Changes in the electro-encephalogram with syncope due to a critical fall in blood pressure produced by pressure on a hyperactive carotid sinus reflex. Record labelled $E$. $E$. $G$. is the electro-encephalogram from the mid-frontal region (indifferent lead on the ear). The simultaneous record of the heart rate is marked $E . K . G$. The tracings are continuous in time ; one-second time calibration is at the lower right corner. The excursion of the electroencephalograph with $50 \mu \mathrm{v}$ is given at the upper right corner. Signals as labelled on the record.

amplified the preliminary observations of Gibbs, Davis, and Lennox (1935) by taking simultaneous electrocardiograms and electro-encephalograms. The results are much the same in cases of orthostatic hypotension and of carotid sinus reflex of the cardiac type. The cardiac standstill and the acute fall in blood pressure in the carotid sinus cases are not at first followed by changes of the electrical rhythm of the brain, other than a somewhat faster rhythm which accompanies states of increased attention. Six or eight seconds after the heart has stopped beating consciousness is lost abruptly, and at the same time the rate of electrical waves is reduced from the normal eight to twelve a second to an abnormal three to four a second. Fig. 1 illustrates a case in which, following pressure over the sinus, there was bradycardia and a fall of $50 \mathrm{~mm} . \mathrm{Hg}$. in the systolic blood pressure. Consciousness was lost after 16 seconds, simultaneous with a great slowing of the rate of cortical electrical 
waves. What is not shown in this figure is that shortly after the appearance of the large slow waves, which become progressively slower, the record flattens ; the large slow waves reappear, however, and increase in frequency as the subject returns toward consciousness, eventually to regain the normal frequency and amplitude as full consciousness is regained.

As for the effect of an increase of cerebral venous pressure, the extent to which the observed mental changes associated are due to inadequate supply of blood and how much to the direct injury of nerve cells has been inadequately studied. Patients in coma from a cerebral injury or with a tumour do not necessarily have an abnormally low oxygen saturation of the blood in the internal jugular veins (Lennox and Williams, 1938). This does not prove, however, that the brain as a whole has had an adequate supply of blood and oxygen. The blood supply to certain areas may have been cut off, leaving a normal blood flow through other areas. However, although the circulatory disturbance may not be widespread, the alteration in the activity of nerves, as indicated both by neurological tests and by a study of cerebral action potentials certainly is widespread. The important question, therefore, would seem to be, not is there a local disturbance of a circulatory nature, but, rather, how does such a local disturbance interfere with activity throughout the whole brain.

\section{The Importance of Various Constituents of the Blood}

Blood is necessary to the brain not because of its mass but because of what it contains. An important but inadequately explored field is the effect on function of the brain of an increase or a decrease of a single constituent of the blood. The metabolism of the brain differs in certain features from the metabolism of other tissues, and the nerve cells are unusually sensitive to alterations of their food supplies. The electrical activity and hence the proper functioning of the many neurones is primarily dependent upon the tensions of oxygen and of carbon dioxide, the concentration of glucose and of electrolytes, and the permeability of their membranes. Likewise Dusser de Barenne et al. (1937) have demonstrated the close correlation between the $p \mathrm{H}$ of the cortex and its electrical activity. Observations in human subjects have been limited ; inferences must be drawn with caution because the particular constituent or event being measured is but one link of a closely joined and mutually interacting chain of events. Observations which we shall now report are but preliminary.

Carbon dioxide.- In affairs of the brain, carbon dioxide has received less publicity than oxygen. Yet if we confine ourselves to states of cerebral activity in which consciousness is present, we find that variations of carbon dioxide produce greater changes in the rate both of cerebral blood flow and of cortical electrical waves than variations in oxygen. Lennox and E. L. Gibbs (1932) observed in human subjects that an increase in the carbon dioxide content of arterial blood caused a great and invariable increase in blood flow through the brain and coincidentally a decrease in the flow of the leg. Decreasing the carbon dioxide content in arterial blood by voluntary hyperpnea caused the opposite effect (Fig. 2). The findings are supported by changes in the colour 
of retinal veins observed by Cobb and Fremont-Smith (1931). In sharp contrast, we observed that changes in the oxygen content of arterial blood resulted in moderate changes in cerebral blood flow, usually without reciprocal alterations in brain and leg. These findings, based on the gaseous content of arterial and venous blood, were later substantiated by Gibbs et al. $(1935 c)$ by means of the thermo-electric flow recorder. The beneficial effect of an increased concentration of carbon dioxide is remarkable. Mental performance, impaired by anoxæmia, is restored by the addition of 3 per cent. carbon dioxide

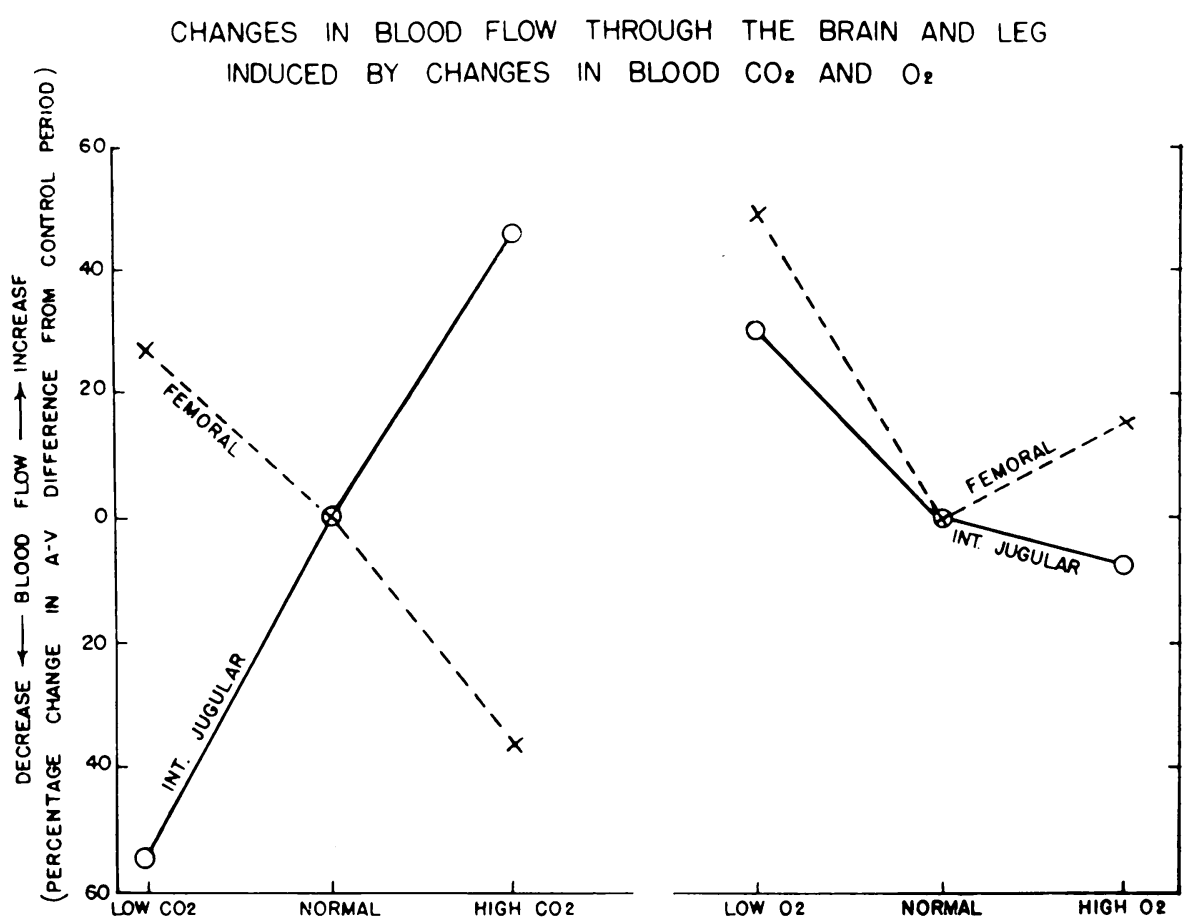

Fig. 2.-Changes in blood flow through the brain and leg induced by changes in $\mathrm{CO}_{2}$ and $\mathrm{O}_{2}$ content of arterial blood. The values are the average of from four to ten experiments in which subjects breathed high or low concentrations of either $\mathrm{CO}_{2}$ or $\mathrm{O}_{2}$ (four procedures). Blood was drawn from an artery or an internal jugular vein before and during the procedure, and the A-V difference calculated. In both figures the circle at the centre marks the preliminary values, and the end of the line the values during the breathing. The ordinate measures the percentage change in the A-V difference from the values obtaining in the preliminary period. Positive percentages indicate a decrease in A-V differences and an increase in the speed of blood flow. Solid lines indicate changes of flow in an internal jugular vein, dashed lines changes in a femoral vein.

to the air breathed (Gellhorn, 1937). Patients can be roused from simple stupor (Loevenhart et al., 1929 ; D'Elseaux and Solomon, 1933) and petit mal seizures inhibited (Lennox, 1928) by breathing mixtures rich in carbon dioxide.

The rate of cortical electrical potentials, both normal and abnormal, is greatly influenced by changes in the concentration of carbon dioxide in the alveolar air (Gibbs, Davis, and Lennox, 1935 ; Gibbs et al., 1935a). Because changes in carbon dioxide tension have such a profound effect both on electrical 
potentials and on cerebral blood flow, the inter-influence of carbon dioxide, of blood flow, and of cerebral activity need elucidation. As a result of studying the effect of various drugs on cerebral circulation and on the cortical electrical activity of the brain, we believe that although changes in action potentials of the brain may parallel circulatory changes, the two cannot ordinarily be directly correlated. In the case of carbon dioxide, however, there is a correlation the understanding of which increases greatly our knowledge of blood and brain relationships.

Data based on the concentration of carbon dioxide in the respired air or on the carbon dioxide content of blood taken from an artery or an arm vein are misleading. The carbon dioxide tension in the brain is most nearly mirrored by the carbon dioxide content of the blood from the internal jugular vein. We have observed that the sharp decrease in the carbon dioxide content of the arterial blood which accompanies hyperpnea is not followed by a decrease of similar magnitude in the carbon dioxide content of the internal jugular blood. This is because the flow of the blood through the brain has been slowed and carbon dioxide has accumulated in the venous portion of the capillaries. An opposite correction obtains when the carbon dioxide content of arterial blood is increased. Fig. 3 shows the relative carbon dioxide content of blood from an artery and from an internal jugular vein in experiments in which the gaseous content of the arterial blood was altered by over-ventilation of the lungs or by breathing increased concentrations of carbon dioxide. Each dot denotes the percentage change of carbon dioxide content in both artery and vein from the value determined before the unusual breathing took place. The chart is much wider than it is tall, which means that the changes of carbon dioxide content which occurred in arterial blood were greater than the changes in venous blood. This disproportion is most distinct in the central portion of the ordinate. Outside the central zone, changes of carbon dioxide concentration which occur in the vein are proportional to those occurring in the artery. Limitations of changes of vessel calibre and of blood pressure may limit the changes of venous carbon dioxide which occur, but another factor is the influence of the oxygen tension. Three of the points in the lower left corner of the chart are out of line. These were bloods in which the oxygen saturation in the internal jugular blood during hyperpnea was very low. As the oxygen saturation approaches 30 per cent. (and the subject approaches unconsciousness), the cerebral vessels do not continue to constrict, an observation which agrees with data obtained by other methods.

These facts indicate that the carbon dioxide tension in the pericapillary spaces is kept relatively stable. The purpose of these circulatory changes is to protect the brain from marked alterations in carbon dioxide tension. Changes in carbon dioxide tension, therefore, produce changes in the electrical activity of the brain in spite of, and not because of, cerebral circulatory adjustments.

It might be argued that the relatively high carbon dioxide content of internal jugular blood which attends hyperpnea is due not to a slower blood flow through the brain but to a transfer of carbon dioxide from the tissues to the venous blood. This point can be clarified by computing the amount of 
carbon dioxide which comes from the combustion of oxygen ; in other words, by computing the respiratory quotient. The increase of carbon dioxide in the venous blood over the level in the arterial blood divided by the decrease of oxygen in the venous blood from the level in the arterial blood gives this quotient. Lennox and Leonhardt $(1931 b)$ ascertained that the respiratory quotient of the human brain calculated in this fashion is close to unity, 0.95 ,
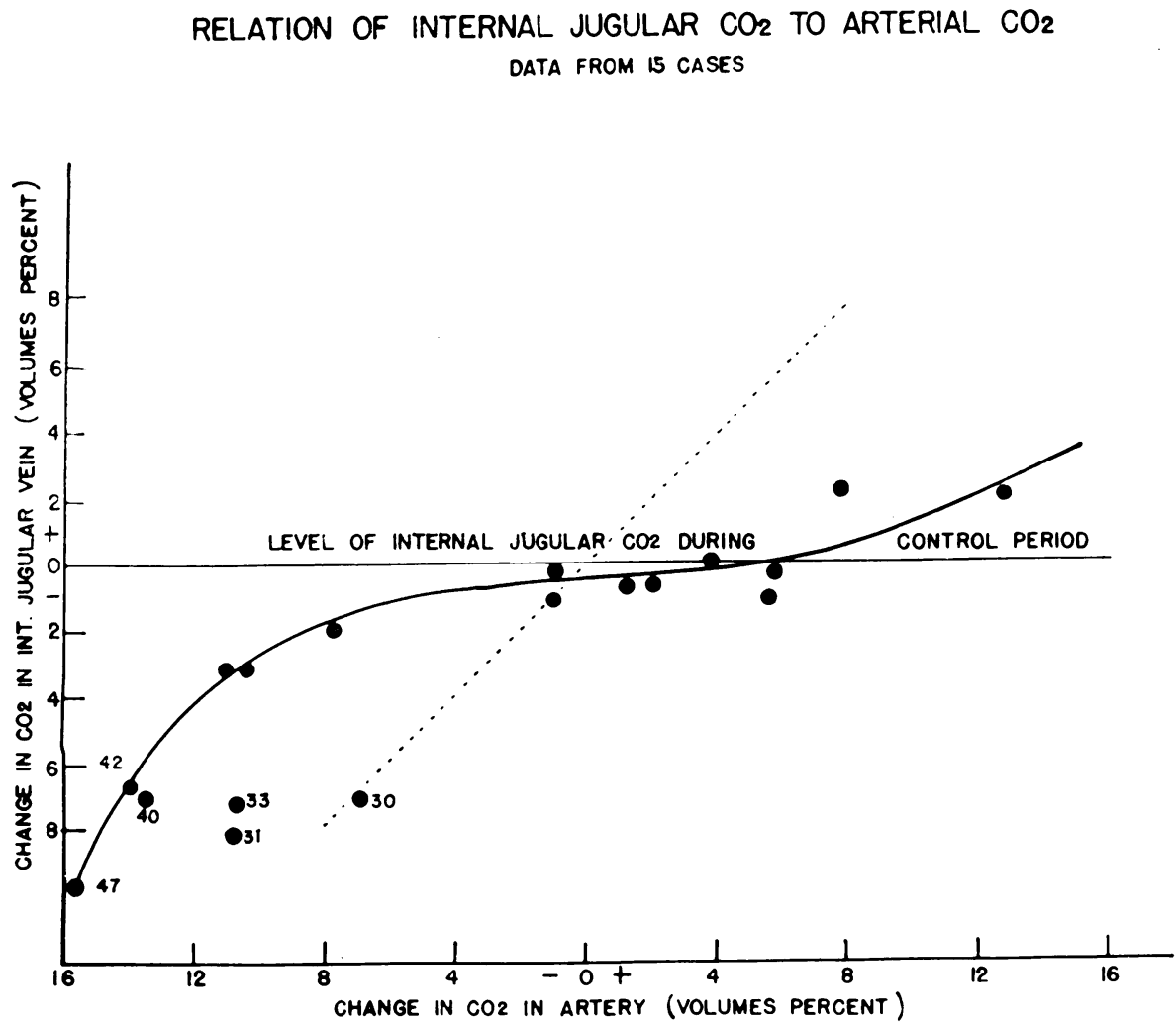

Fig. 3.-The relation of the $\mathrm{CO}_{2}$ content of blood from an internal jugular vein and from an artery. Data are from 15 cases. Subjects "blew off" $\mathrm{CO}_{2}$ or breathed air containing an increased concentration of $\mathrm{CO}_{2}$. The scales represent the change in the $\mathrm{CO}_{2}$ content of the internal jugular blood (ordinate) and of arterial blood (abscissa) from values obtained before the experiment. Each dot is the resultant of $\mathrm{CO}_{2}$ measurements of four blood samples, i.e. the difference of $\mathrm{CO}_{2}$ in artery and vein before and during the breathing. The figures placed beside the dots in the lower left corner are the values for oxygen saturation of internal jugular blood during hyperpnea. The dotted line indicates a one-to-one relationship.

indicating a combustion exclusively of glucose, and of the leg it is $0 \cdot 87$. They found that whether the subjects " blew off" carbon dioxide from the lungs or inhaled a high carbon dioxide mixture or breathed a low-oxygen mixture, the computed average respiratory quotient for the brain was the same, approximately $1 \cdot 20$. For the leg, however, the quotient was very different with the different procedures. When the subjects breathed 5 to 10 per cent. of carbon dioxide in air the average respiratory quotient was only 0.54 (carbon dioxide absorbed by the tissues). During hyperpnea it was $2 \cdot 21$ (carbon dioxide given 
up by the tissues). During anoxæmia it was $2 \cdot 70$ (oxygen not taken up by the tissues). These data suggest that the brain does not store carbon dioxide or oxygen, and receives preferential treatment when supplies are limited.

Observations of the influence of carbon dioxide changes on the electrical activity of the cortex are even more enlightening, because definite changes in cortical potentials can be correlated with changes in mental and neural activity. We believe a frequency in cortical potentials either abnormally slow or fast, whether or not clinical symptoms are present, indicates an abnormal neurological or psychological state. Specifically, increase in carbon dioxide tension of the blood increases the frequency of the electrical waves of the brain, improves the mental activity of those with abnormally slow frequencies, and interferes with the mental activity of those whose frequencies are already normal. We have plotted frequencies of cortical oscillations against the carbon dioxide content of blood drawn from an internal jugular vein of subjects performing hyperpnea or breathing carbon dioxide. One such experiment is shown in Fig. 4. The average frequency of the electrical waves increases with increased concentrations of carbon dioxide. Therefore, we can say that within a certain normal range of carbon dioxide tension in the brain, electrical activity is exceedingly sensitive to changes in carbon dioxide tension. The effect would be much greater if the brain were not protected by the circulatory adjustments which we have discussed. Outside the usual range of normal carbon dioxide tension, cortical activity is also abnormal, but is less sensitive to further changes. It would appear, then, that normal cerebral activity is balanced on an extremely narrow base as regards carbon dioxide tension, a much narrower base than previous studies have indicated. After a certain amount of over-ventilation, the response of cortical activity varies for different persons. The cause for this individual variability requires further study.

In speaking of carbon dioxide, we emphasize that the gas is important as a participant not only in the oxidative process of cells but also in the acid-base balance of tissues.

Oxygen.-Untoward clinical effects attend oxygen pressures which are either too high or too low. In order to ascertain the degree of cerebral anoxæmia required to produce loss of consciousness, Lennox et al. (1935a) measured the oxygen saturation of blood drawn from the internal jugular vein of subjects during circulatory collapse (fainting or carotid sinus reflex with a critical fall in blood pressure), or during the breathing of nitrogen. Regardless of the cause of the collapse or of the oxygen saturation of the arterial blood, subjects were unconscious when the blood leaving the brain was less than 24 per cent. saturated with oxygen. All were conscious when the value was above 30 per cent. The critical point is, therefore, a sharp one. Patients in coma from non-circulatory causes have values of oxygen saturation well above 35 per cent.

As was stated in the discussion on carbon dioxide, alteration of the oxygen content of arterial blood does not greatly influence the cerebral circulation until extreme anoxæmia is reached. Breathing pure oxygen causes slight decrease in cerebral blood flow and breathing low-oxygen mixtures causes 
Increase in flow in spite of the retarding effect of the accompanying hyperpnea (Lennox and Leonhardt, 1932 ; Gibbs et al., 1935c). When extreme, the degree of oxygen lack in internal jugular blood determines to some extent the
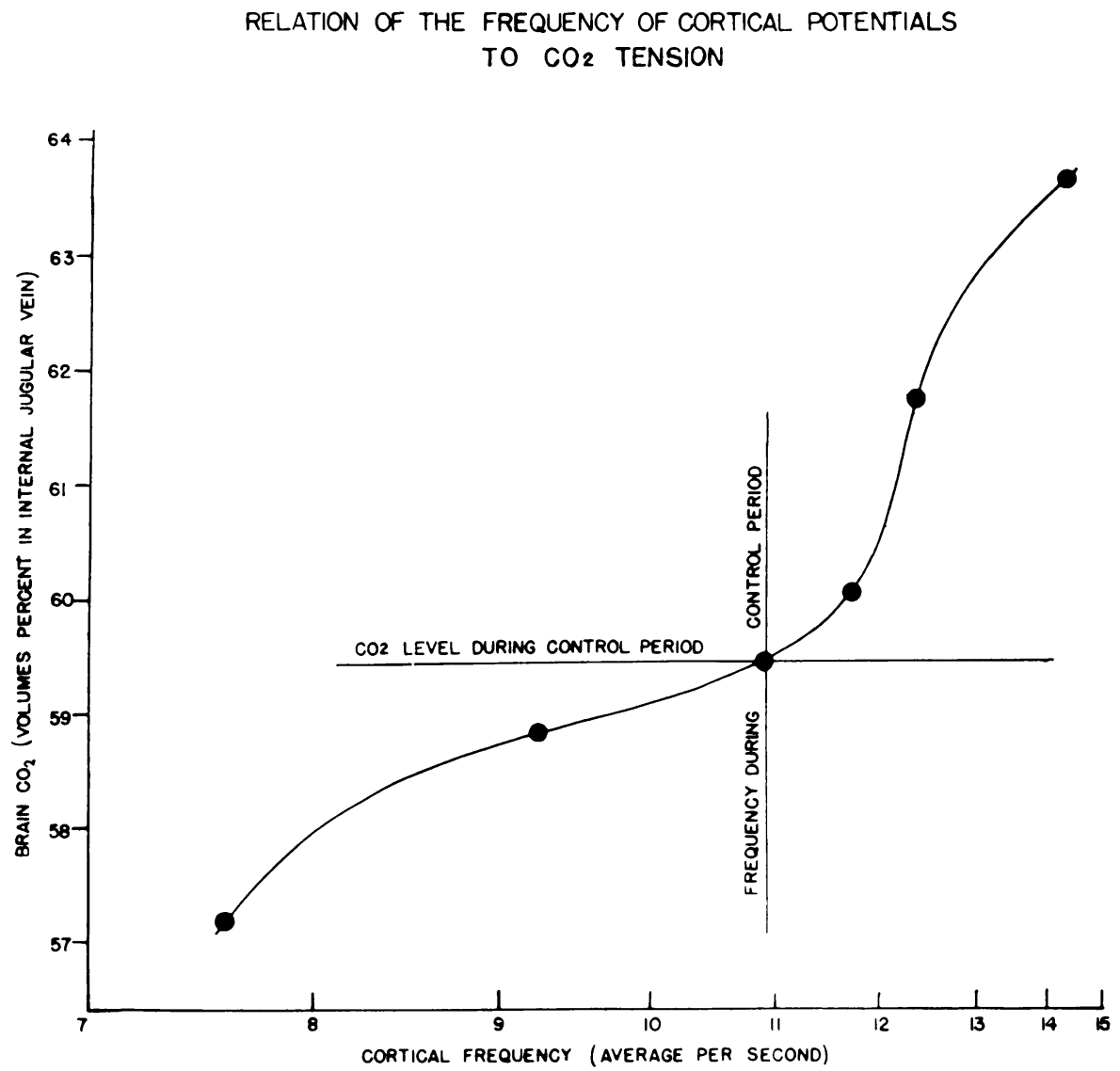

Fig. 4.-The relation of the frequency of cortical potentials to the $\mathrm{CO}_{2}$ content of internal jugular blood ; data from one case who breathed a high $\mathrm{CO}_{2}$ mixture or over-ventilated his lungs. The abscissa represents frequency plotted as the reciprocal of duration of wavelength, which accounts for the non-linear scale. Such a scale is desirable since a change from eight to nine per second is a greater percentage change than from 14 to 15 per second.

Average frequency per second was calculated by counting the duration of all the countable waves in a given length of electrogram from the occipital lead (indifferent electrode on the ear). The ordinate represents the $\mathrm{CO}_{2}$ content of the internal jugular vein in volumes per cent., the best indicator of the $\mathrm{CO}_{2}$ tension of the brain.

As can be seen, a slight change in the $\mathrm{CO}_{2}$ content from the normal control level produces great changes in the cortical frequency, whereas when the $\mathrm{CO}_{2}$ content is either extremely high or extremely low, the cortical frequency is less sensitive to $\mathrm{CO}_{2}$ changes.

degree of disproportion between the carbon dioxide content of arterial and internal jugular blood (Fig. 3).

As for the effect of oxygen on cortical electrical waves, anoxæmia causes a significant slowing of frequency of the waves only when the anoxæmia is so extreme that unconsciousness impends (Fig. 5). The breathing of pure oxygen does not appreciably affect the frequency of brain rhythms. However, arterial 
blood is normally nearly saturated with oxygen, and probably greatly increasing oxygen tension in the blood would increase the frequency of waves. Persons who are mildly intoxicated or are having a grand mal seizure have excessively fast cortical electrical waves (Gibbs et al., 1937). Oxygen and alcoholic intoxication are each accompanied by euphoria and clumsy mental reactions, and frequently by convulsions (Lennox and Behnke, 1936).

Because moderate changes in oxygen tension have no appreciable effect on
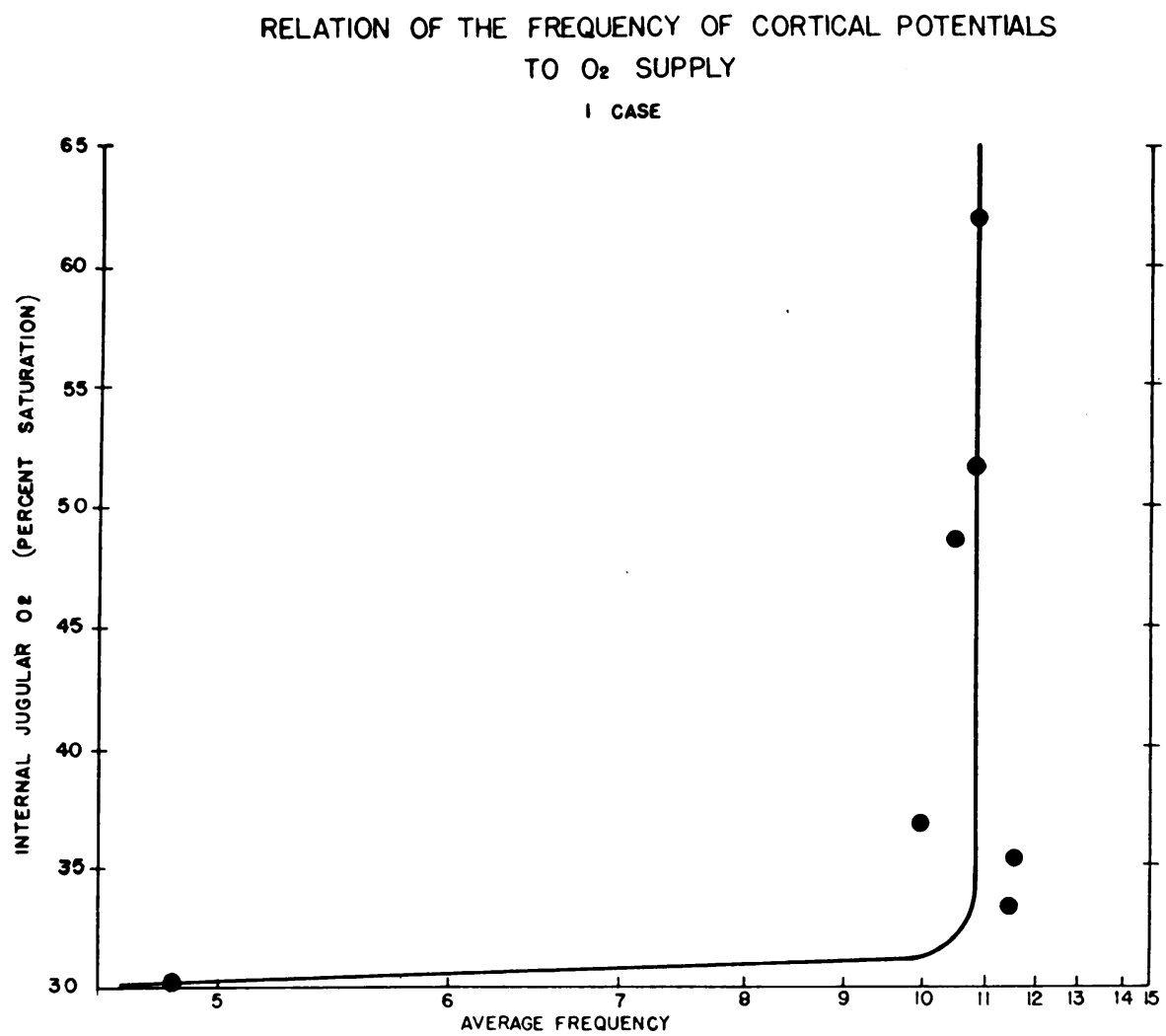

Fig. 5.- Relation of frequency of cortical potentials to the $\mathrm{O}_{2}$ saturation of the internal jugular blood in one case. The average frequency of cortical potentials was calculated as in Fig. 4 and is represented on the abscissa scale. The $\mathrm{O}_{2}$ saturation of blood from the internal jugular vein (ordinate) is used as an indicator of the $\mathrm{O}_{2}$ supply of the brain. The effect of low $\mathrm{O}_{2}$ on cortical frequency is critical, but is manifest only when the internal jugular $\mathrm{O}_{2}$ has fallen to about 30 per cent. saturation, which approaches the level at which consciousness is lost.

the electrical activity of the cortex the cerebral circulation does not need to (and in fact does not) make adjustment for moderate changes in the oxygen content of arterial blood. The relationship of the oxygen saturation in arterial and internal jugular blood is shown in Fig. 6. For ranges of arterial oxygen which are above 70 per cent. saturation, there is no consistent relationship. Oxygen values in the blood leaving the brain are dominated by carbon dioxide values in the arterial blood. A 51 per cent. carbon dioxide value is accom- 
panied by an oxygen saturation farthest to the left of the diagonal line, representing an increased cerebral blood flow ; a 42 per cent. value is farthest to the right, a decreased flow. In conditions of anoxæmia, the blood oxygen relationships are nearly linear, although, consistent with other observations, a very low arterial oxygen value is accompanied by a relatively higher internal jugular value, indicating an increased cerebral flow.

Sugar.-Moderate and temporary increase in blood sugar does not seem

RELATION OF INTERNAL JUGULAR O2 TO ARTERIAL O2

14 CASES

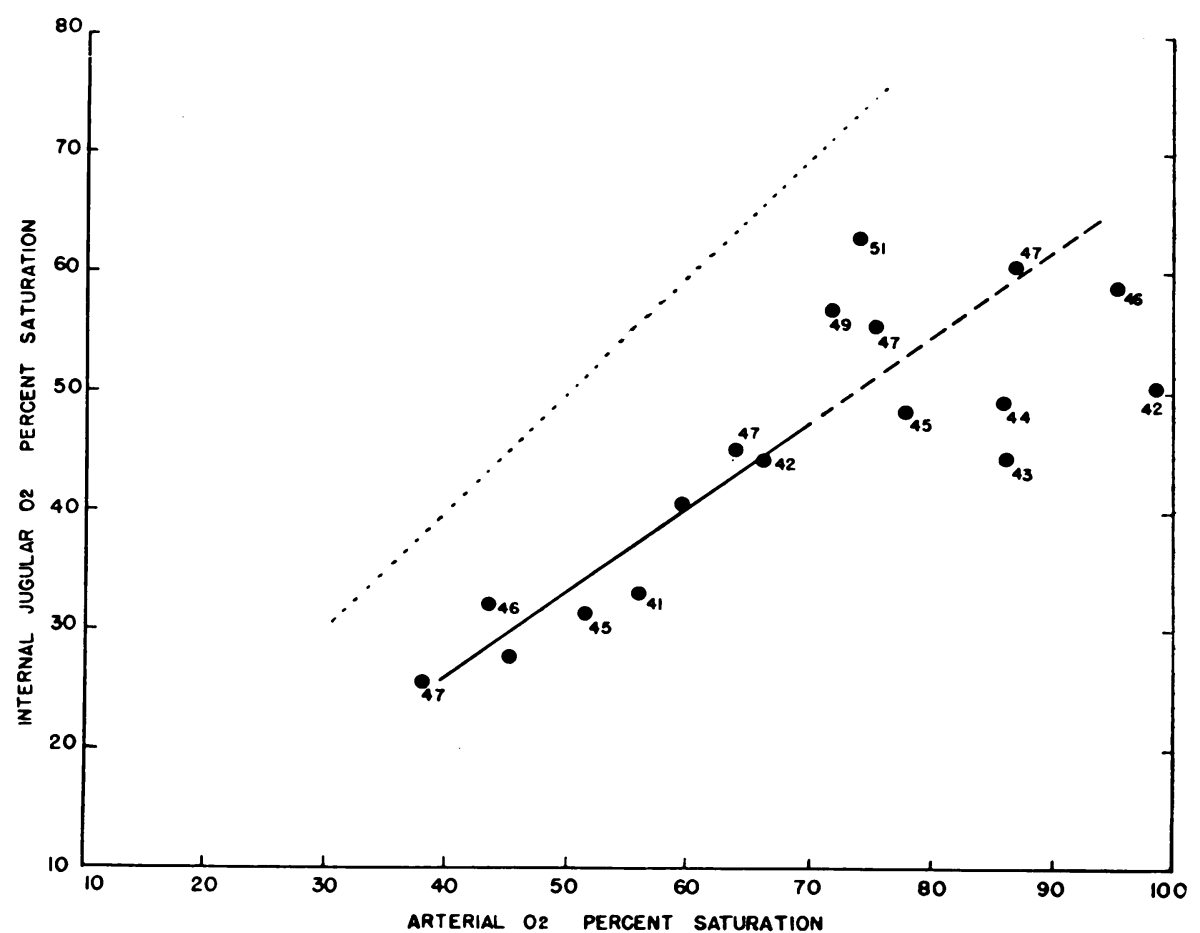

Fig. 6.- Relation of the oxygen saturation of internal jugular vein blood and of arterial blood in 14 cases in which subjects breathed air either rich or poor in oxygen. The oxygen saturations in per cent. are indicated on the ordinate for internal jugular and on the abscissa for arterial blood. The numerals beside the dots indicate the carbon dioxide content of the arterial blood during the breathing. The dotted line indicates a one-to-one relationship.

to influence normal cerebral function. Critical decrease, on the other hand, is attended by nervous and mental symptoms which are well known. Electroencephalographic observations made by Hoagland (1937) on schizophrenic patients show abnormally slow frequencies during the period of insulin reaction. Our own observations on normal subjects and on epileptics are in agreement with Hoagland's. We have, however, correlated the frequency of cortical electrical waves with the glucose content of blood, drawn not from an arm vein but from an internal jugular vein. We find that only at levels of blood 
glucose below $50 \mathrm{mg}$. per cent. is the electrical activity of the cortex altered (Fig. 7).

The glucose content of the arterial blood when plotted against its content in the internal jugular blood (Fig. 8) gives a straight-line one-to-one relationship. Assuming that undue amounts of glucose are not used by the brain in hypoglycæmia, these observations indicate that the brain interposes no circulatory defence against alterations of its supply of glucose.

RELATION OF THE FREQUENCY OF CORTICAL POTENTIALS

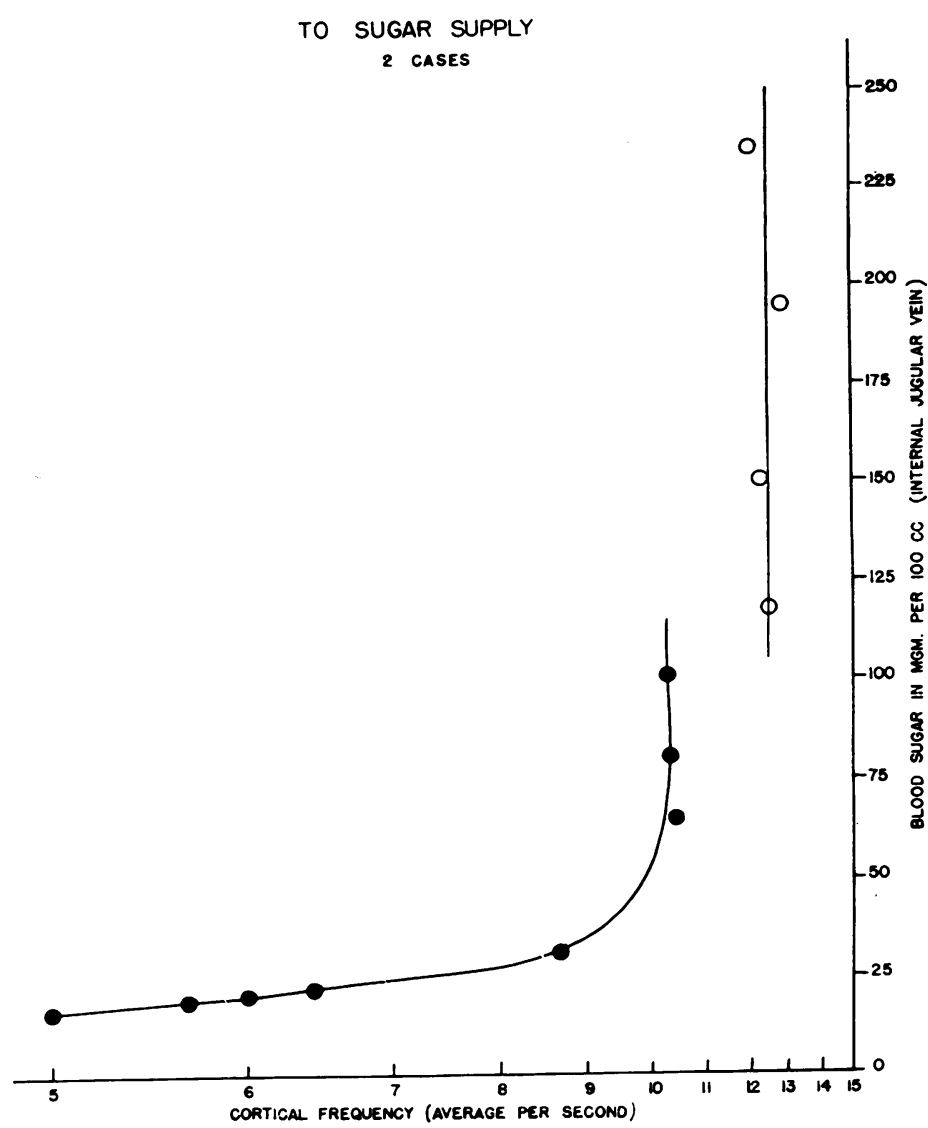

Fig. 7.-The relation of the frequency of cortical potentials to the concentration of sugar in the blood from the internal jugular vein. The data are from two cases indicated by the open and by the solid dots.

Cortical frequency (abscissa) is plotted as in Fig. 4. The amount of sugar in the internal jugular vein (ordinate) is here used as an indicator of the sugar supply to the brain. As can be seen, low sugar alteıs cortical frequency only at a critically low level.

\section{Comment}

Under normal conditions, the circulation in the brain is probably more constant and steady than the circulation in the arm or leg (Lennox, 1936). Unlike the muscles (except those of the heart), the brain is always active ; its functional needs are always nearly maximal and the capillaries always open. 
Cerebral activity can hardly be related to such fortuitous changes in the total cerebral circulation as occur in normal activity of the brain or body. Even intermittent changes in activities, such as sleep and seizures, are initiated without benefit of gross circulatory changes. Gross changes which occur in the total cerebral blood flow are probably not adjustments to nutritional require-

RELATION OF INTERNAL JUGULAR SUGAR TO ARTERIAL SUGAR DATA FROM I CASE

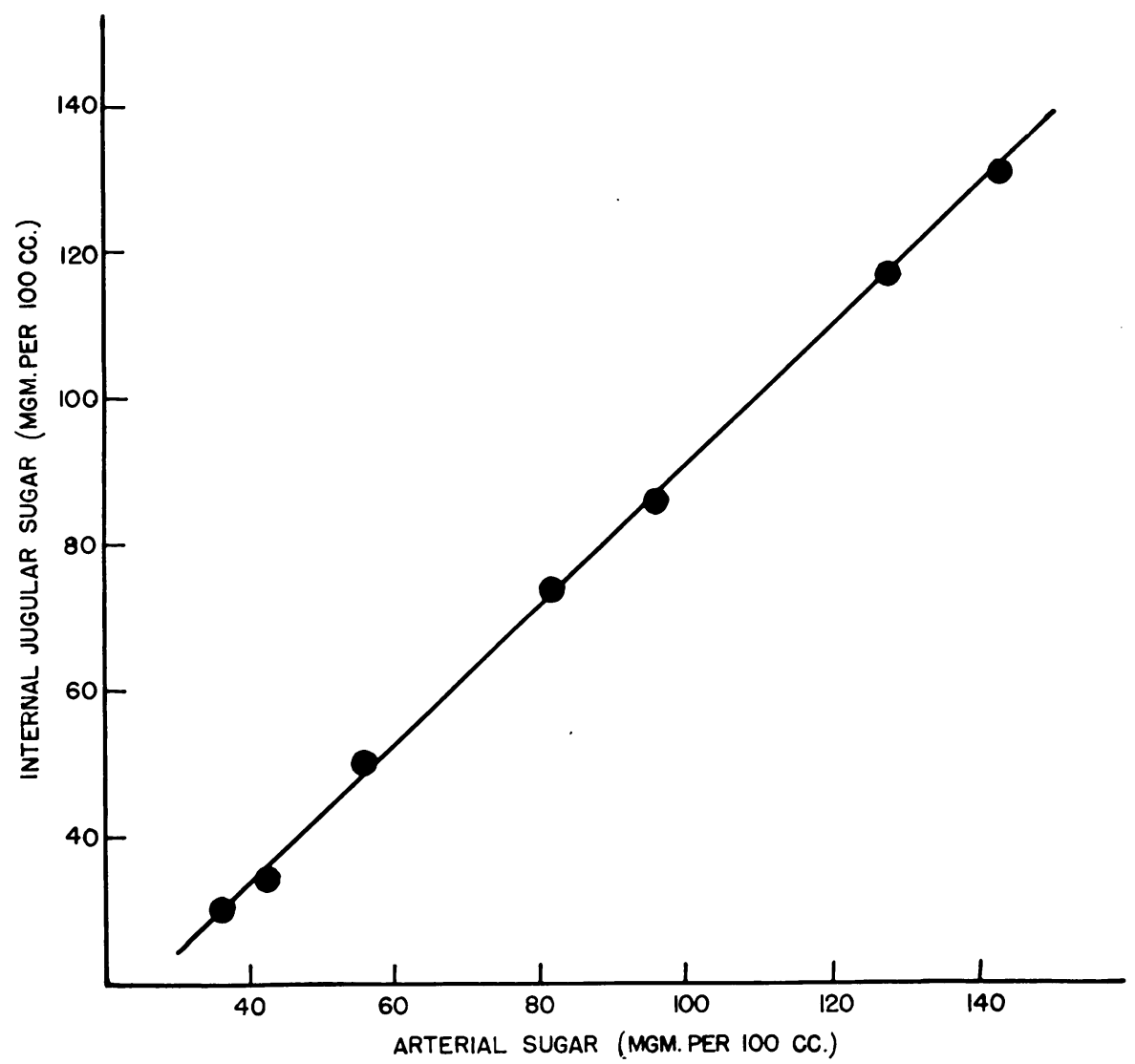

Fig. 8.- Relation of the concentration of sugar in internal jugular and in arterial blood. Arterial blood sugar measurements are plotted on the abscissa and internal jugular blood sugar on the ordinate in the case of a subject who was given insulin.

This straight-line curve indicates that there is no circulatory mechanism interposed between artery and brain to protect the brain against a low concentration of arterial sugar and that with arterial sugar levels low enough to give rise to cerebral symptoms, there is no diminution in the ability of the brain to use sugar.

ments of the nerve cells, but are directed towards a maintenance of constant carbon dioxide tensions and a constant $p \mathrm{H}$ of the nerve cells. Changes in blood flow which may occur in response to alterations in nutritional requirements are probably local.

Within the limits of clear consciousness, the greatest alterations of cerebral 
blood flow attend alterations of alveolar carbon dioxide. If we consider oxygen as all-important, the action of carbon dioxide is inexplicable. For example, hyperpnea " blows off" carbon dioxide from the lungs and produces alkalosis, which in itself accentuates abnormal nervous phenomena. Yet the response of the cerebral circulation to hyperpnea is a constriction of cerebral arterioles and a stagnation of cerebral circulation. This strange action of carbon dioxide is explained when cortical action potentials are studied. Relatively slight variations in alveolar carbon dioxide influence the rate of cortical rhythms. Yet maintenance of a normal rate of the rhythms is essential for normal cerebral function. Therefore, by speeding or retarding cerebral blood flow the circulation helps to stabilize the carbon dioxide tension and the acidbase balance in the brain and allows the brain to function more normally.

In sharp contrast is the rôle of oxygen. Neither the circulation nor the electrical activity of the brain nor yet consciousness is greatly affected by variations in the oxygen concentration of the blood leaving the brain, provided the saturation is above 30 per cent. The same statement applies to glucose for concentrations above $50 \mathrm{mg}$. per cent.

\section{Conclusions}

The brain through its autonomic nervous connections should be regarded as an active rather than a passive agent in alterations of cerebral blood flow. The brain influences circulation, but within normal limits the circulation does not influence cerebral activity.

In mental activity, the total cerebral blood flow through the brain is probably increased as a result of an accumulation of carbon dioxide in cerebral tissues or because of an increase in systemic blood pressure. The increased flow presumably plays a passive and not an active part in increased mental work.

The total cerebral blood flow is not significantly decreased prior to intermittent changes in cerebral activity, such as sleep, narcoleptic and epileptic seizures.

The influence of alterations of certain blood constituents on clinical symptoms and on the electrical activity of the cortex has been studied. Increase in the carbon dioxide content of arterial blood causes a pronounced increase in the blood flow in the brain (and a decrease in the extremities) and an increase in the rate of cerebral electrical potentials. A decrease in carbon dioxide tension has the reverse effect. The alterations of cerebral blood flow serve to protect the brain against variations in carbon dioxide tension and in $p \mathrm{H}$. With over-ventilation, for example, cerebral blood flow is slowed, and the accumulation of carbon dioxide in the capillaries increases the carbon dioxide tension in the brain and modifies the extreme decrease in arterial carbon dioxide (and the alkalosis) induced by the over-ventilation.

Moderate changes in the oxygen or the glucose content of internal jugular blood do not cause significant alterations in the cerebral circulation or in the electrical activity of the brain. Anoxæmia sufficient to affect consciousness is 
attended by increased circulation and a slowing of cortical action potentials Hypoglycæmia is attended by a slowing of the electrical waves of the cortex.

Further advances in this subject will require careful analysis of the relative influence of various blood constituents and chemical processes on the metabolism and on the electrical activity of nerve cells.

A paper read before the Assosiation for Research in Nervous and Mental Diseases, New York City, 27th December, 1937. Aid was received from the Josiah Macy, Jr., and the Rockefeller Foundations.

\section{REFERENCES}

Behnke, A. R., Johnson, F. S., Poppen, J. R., and Motley, E. P. (1935). Amer. J. Physiol., 110, 565 .

Carmichael, E. A., Doupe, J., and Williams, D. (1937). J. Physiol., 91, 186.

Cobb, S., and Fremont-Smith, F. (1931). Arch. Neurol. Psychiat., 26, 731.

Dusser de Barenne, McCulloch, W. S., and Nims, L. F. (1937). J. cell. and comp. Physiol., $10,277$.

D'Elseaux, F. C., and Solomon, H. C. (1935). Arch. Neurol. Psychiat., 29, 213.

Fulton, J. F. (1928). Brain, 51, 310.

Gellhorn, E. (1937). Amer. J. Psychiat., 93, 1,413.

Gibbs, F. A., Lennox, W. G., and Gibbs, E. L. (1934). Arch. Neurol. Psychiat., 32, 257.

Gibbs, F. A., Gibbs, E. L., and Lennox, W. G. (1935b). Brain, 58, 44. (1935c). Amer. J. Physiol., 111, 557.

(1935a). Amer. Heart J., 10,916.

Gibbs, F. A., Davis, H., and Lennox, W. G. (1935). Arch. Neurol. Psychiat., 34, 1,133.

Gibbs, F. A., Gibbs, E. L., and Lennox, W. G. (1937). Arch. intern. Med., 60, 154.

Hoagland, H., Cameron, D. E., and Rubin, A. M. (1937). Amer. J. Psychiat., 94, 183.

Lennox, W. G. (1928). J. clin. Invest., 6, 23.

Lennox, W. G., and Leonhardt, E. L. (1931b). Arch. Neurol. Psychiat., 26, 719. (1931a). Ibid., 26, 725.

Lennox, W. G., and Gibbs, E. L. (1932). J. clin. Invest., 11, 1,155.

Lennox, W. G., Gibbs, F. A., and Gibbs, E. L. (1933a). Arch. Neurol. Psychiat., 34, 1,001.

Lennox, W. G., Gibbs, E. L., and Gibbs, F. A. (1935b). J. Pharmacol., 53, 113.

Lennox, W. G., and Behnke, A. R., Jr. (1936). Arch. Neurol. Psychiat., 35, 782.

Lennox, W. G., and Gibbs, E. L. (1936). Ibid., 36, 13.

Lennox, W. G. (1936). Ibid., 36, 375.

Lennox, W. G., Gibbs, F. A., and Gibbs, E. L. (1936a). Ibid., 36, 1,236.

Lennox, W. G., and Williams, D. (unpublished observations).

Loevenhart, A. S., Lorenz, W. F., and Waters, R. M. (1929). J. Amer. med. Ass., 92, 880. 